\title{
Expressões idiomáticas com a temática alimentação: tradução e glossário de "Pepinos e Abobrinhas", de Márcio Alemão
}

\section{Idiomatic expressions related to food: translation and glossary of "Hot Potatoes and Baloney”, by Márcio Alemão}

Janaína Madeiro da Silva* Elisa Duarte Teixeira**

\footnotetext{
* Bacharel em Letras - Línguas Estrangeiras Aplicadas ao Multilinguismo e à Sociedade da Informação (LEA-MSI), pela Universidade de Brasília. E-mail: janaina.madeiro@gmail.com

** Professora Adjunta de Tradução - Inglês do Departamento de Línguas Estrangeiras e Tradução (LET) e orientadora junto ao Programa de Pós-Graduação em Estudos da Tradução (POSTRAD) do Instituto de Letras da Universidade de Brasília. E-mail: elisadut@unb.br
}

$$
\begin{gathered}
\text { TradTerm, São Paulo, v.37, n. 2, janeiro/2021, p. 397-429 } \\
\text { Número Especial - Linguística de Corpus } \\
\text { www.revistas.usp.br/tradterm }
\end{gathered}
$$


Resumo: Expressões Idomáticas (Els) são um desafio para aprendizes de língua estrangeiras e de tradução. $O$ objetivo geral deste trabalho foi fazer um estudo contrastivo das Els encontradas no texto "Pepinos e abobrinhas" (ALEMÃo 2005) ao traduzi-lo para o inglês. Primeiramente buscamos definições e equivalentes em fontes de consulta online e fizemos uma primeira versão da tradução. Em seguida, compilamos um corpus paralelo multiversão com traduções do mesmo texto feitas por outros aprendizes, comparando suas propostas tradutórias com as nossas para produzir uma versão final do texto. As informações coletadas nesse percurso foram organizadas na forma de um glossário, disponível no site do Projeto TermiTraDiCo. Os resultados corroboram nossa hipótese de que estudantes de tradução enfrentam obstáculos ao trabalharem com Els, particularmente quando são de uma temática específica, seja pela dificuldade de recuperarem seu significado na língua do texto de partida, seja pela ineficiência das fontes de consulta em citá-las e/ou oferecer equivalentes adequados na língua de chegada.

Palavras-chave: Estudos constrastivos português-inglês; Corpus de aprendizes de tradução; Fraseologia; Expressões idiomáticas; Alimentação; Glossário.

Abstract: Idiomatic Expressions (IEs) are a challenge for translation and foreign language learners. The main goal of this article was to carry out a contrastive study of the IEs found in the text "Pepinos e abobrinhas" (ALEMÃO 2005) while translating it into English. For the first version of the text, we looked for definitions and equivalents for the IEs in online sources. Then, we compiled a multi-version parallel corpus with several translations of the same text produced by apprentices. We used it to compare the equivalents the apprentices chose with our own, and then produced our final version of the translated text. The information collected during this process was organized in a glossary, available at the TermiTraDiCo Project website. The results confirm our hypothesis that translation learners face many obstacles when working with IEs, especially if they belong to a specific thematic area, both because it is difficult to retrieve their meaning in the source language text, and because dictionaries do not list them and/or do not offer adequate equivalents in the target language.

Keywords: Portuguese-English Contrastive Studies; Translation Learner Corpus; Phraseology; Idiomatic Expressions; Food; Glossary.

TradTerm, São Paulo, v.37, n. 2, janeiro/2021, p. 397-429

Número Especial - Linguística de Corpus

www.revistas.usp.br/tradterm 


\section{Introdução}

Aprender uma língua estrangeira nem sempre é "mamão com açúcar". Traduzir textos, então, pode obrigar a pessoa a "pular da panela para o fogo". Em ambos os casos, as expressões idiomáticas (Els) são, reconhecidamente, um "angu de caroço". Por isso, decidimos "colocar a mão na massa" e começar a "descascar esse abacaxi".

Estudos linguísticos têm mostrado, de diferentes perspectivas, que a comunicação não se dá por meio de palavras aleatórias nem isoladas, mas por agrupamentos pré-fabricados de itens lexicais que ocorrem juntos porque, de alguma maneira, mantêm uma relação entre si (Cf. por exemplo, BAKER 1992). Esses agrupamentos muitas vezes possuem um alto grau de fixidez e suscitam significados não transparentes; isto é, o sentido total da combinatória não pode ser depreendido do sentido literal de seus componentes. Este é o caso das expressões idiomáticas (doravante Els). Os fraseologismos, que incluem expressões idiomáticas e também provérbios e ditados populares, entre outros, conforme definidos por Ortíz Alvarez, "são unidades lexicais múltiplas que apresentam vários graus de transparência semântica que vão de maior transparência à total opacidade" (ORTíz Alvarez 2000: 70). A área de estudos linguísticos que dedica-se às Els é a Fraseologia, que, por sua vez, é uma subárea da Lexicologia. Ainda segundo esta autora (ORTíz Alvarez 2000: 91), a Fraseologia divide-se em dois ramos: a fraseologia comum, ou popular (da qual fazem parte as frases feitas, as Els e os provérbios, por exemplo), e a fraseologia ou terminologia especializada (que é recuperada a partir de textos especializados e incorporada a dicionários de especialidade ou bancos de dados terminológicos). Este trabalho se insere no campo da fraseologia comum, ou popular.

Devido à opacidade de sentido das Els, e por serem culturalmente marcadas, exigem uma atenção redobrada, tanto no aprendizado de línguas estrangeiras quanto na prática tradutória. Isso porque idiomatismos não podem ser traduzidos literalmente, fazendo-se necessário, primeiramente, compreender como são expressos e compreendidos na língua e cultura de partida, para que se possa, então, traduzi-los de uma maneira eficaz (XATARA; RIVA; RIOS 2001).

\footnotetext{
TradTerm, São Paulo, v.37, n. 2, janeiro/2021, p. 397-429

Número Especial - Linguística de Corpus

www.revistas.usp.br/tradterm
} 
Assim, o objetivo geral deste trabalho foi fazer um estudo contrastivo de Els e refletir sobre as complexidades envolvidas em traduzi-las do português brasileiro para o inglês americano, com um foco especial em expressões que possuem em sua composição alguma palavra do campo semântico da alimentação. 0 ponto de partida para a escolha dessa temática, e que serviu de base para o levantamento das expressões pesquisadas, foi o texto "Pepinos e abobrinhas", de Marcio Alemão, publicado na seção Refogado da revista Carta Capital, em 13 de abril de 2005 (vide coluna 1 do Apêndice I), que nos propusemos a traduzir para o inglês. Ao se observar como é estruturado, fica claro que, para traduzir um texto como esse é preciso levar em conta o jogo intrincado de Els nele presentes, atentando-se para o fato de que, além de constituírem um diálogo plausível, contêm palavras que, em sua maioria, possuem alguma relação com a alimentação, ainda que o sentido idiomático da El como um todo não leve em conta (ou não tenha ligação direta) com esse campo semântico no contexto de uso. Tendo em vista essas dificuldades, e partindo da hipótese de que localizar traduções ou mesmo definições para as Els nos dicionários disponíveis não seria uma tarefa fácil (pela forma como, no geral, estão organizados), fizemos um levantamento das Els encontradas no referido texto com vistas à elaboração de um material de consulta online para aprendizes de tradução e de língua estrangeira no par de línguas Português $\rightarrow$ Inglês. Para tanto, elaboramos também duas versões (para o inglês) desse texto, sendo que a segunda foi criada após explorarmos um corpus paralelo multiversão, compilado por nós, contendo outras traduções do mesmo texto feitas por estudantes da disciplina de Prática de Tradução Português $\rightarrow$ Inglês de Textos Gerais (doravante PT $P \rightarrow I$ Gerais), do curso de Tradução-Inglês do Departamento de Línguas Estrangeiras e Tradução do Instituto de Letras da Universidade de Brasília, ministrado por uma das autoras deste artigo.

Percebemos, por meio da análise desse corpus, que havia várias outras possibilidades mais adequadas de tradução das expressões encontradas no texto de partida proposta pelos aprendizes, o que motivou criarmos uma segunda versão da tradução (vide colunas 2 e 3 do Apêndice I). Acreditamos que o material resultante, organizado na forma de glossário online consultável a partir do texto de partida, ou por busca textual, contribui para os estudos contrastivos das Els,

TradTerm, São Paulo, v.37, n. 2, janeiro/2021, p. 397-429

Número Especial - Linguística de Corpus

www.revistas.usp.br/tradterm 
seja no âmbito dos estudos da tradução ou do ensino e aprendizagem de português ou inglês como língua estrangeira, seja para nutrir a curiosidade daqueles que têm interesse pelo assunto.

\section{Justificativa}

Expressões idiomáticas são conhecidas por apresentarem dificuldades para o entendimento, tanto para os que estão aprendendo uma língua estrangeira quanto, em alguns casos, para os próprios falantes nativos, em sua própria língua materna. Isso se deve ao fato de essas expressões terem graus variados de idiomaticidade; isto é, não são transparentes semanticamente, além de serem culturalmente marcadas e convencionadas (ORTíz Alvarez 2000; RIVA 2009; TAGNIN 2013). A importância de seu estudo é, portanto, evidente.

O estudo das unidades fraseológicas (doravante UFs), onde se incluem as Els, bem como de pesquisas contrastivas comparando o uso de UFs em línguas distintas, têm feito avanços significativos desde meados dos anos de 1980, conforme menciona Riva (2009: 17):

No Brasil, também verificamos grande interesse nessa área - para mencionar apenas os pioneiros: Cf. CAMARGO \& STEINBERG (1986), TAGNIN (1987, 1989), XATARA (1994, 1998), RONCOLATTO $(1996,2001)$, ORTIZ ALVAREZ (2000) E VALE (2002).

Tagnin (2013) dedica um capítulo inteiro de seu livro $O$ jeito que a gente diz às Els, devido à importância que essas têm para aprendizes de línguas estrangeiras, tradutores, intérpretes e escritores.

No que tange ao campo semântico da alimentação, no último ENTRAD ${ }^{1}$ houve, inclusive, um simpósio dedicado inteiramente à apresentação de trabalhos e discussões sobre a tradução de idiomatismos envolvendo, também, essa temática.

\footnotetext{
1 Evento que reuniu o XIII Encontro Nacional de Tradutores e o VII Encontro Internacional de Tradutores, organizado pela Associação Brasileira de Pesquisadores em Tradução - ABRAPT e realizado em parceria com a Universidade Federal da Paraíba, em João Pessoa, na primeira semana de outubro de 2019.
}

TradTerm, São Paulo, v.37, n. 2, janeiro/2021, p. 397-429

Número Especial - Linguística de Corpus

www.revistas.usp.br/tradterm 
O texto "Pepinos e abobrinhas", de Alemão (2005), é um exemplar muito didático, divertido e bem construído do uso de Els num diálogo informal. As expressões utilizadas pelo autor apresentam desafios tanto para o entendimento na língua de partida quanto para sua tradução. Tomemos como exemplo o próprio título do texto: sem a devida atenção à idiomaticidade, poderia ser traduzido literalmente por "Cucumbers and Zucchinis" (ou "courgettes", para "abobrinhas", na variante europeia do inglês), pois esses são os equivalentes encontrados em dicionários para essas palavras, quando usadas em seu sentido denotativo / referencial. Sabemos, porém, pelo contexto, que não se trata dos alimentos em si, mas de seu sentido idiomático e metafórico, que poderíamos parafrasear como "problemas e tolices".

A busca pelas Els encontradas no texto "Pepinos e abobrinhas" em dicionários de português (como os que citaremos na continuação) foi um tanto trabalhosa, pois nem sempre traziam informações suficientes para uma boa compreensão. E ainda que esses dicionários nos ajudassem a compreender as Els no texto de partida, como fazer a busca por Els de sentido semelhante na língua de chegada? E mais, seria preciso encontrar Els que tivessem alguma relação, ainda que meramente na forma, com o campo semântico da alimentação. Tendo em vista essas dificuldades e necessidades, tivemos a ideia de construir um material de consulta online que trouxesse informações úteis a tradutores e estudantes de língua inglesa, a partir do estudo e tradução do texto de Alemão (2005) para o inglês.

\section{Fundamentação teórica}

Quando estudamos línguas estrangeiras ou traduzimos, percebemos que o sentido das palavras raramente pode ser derivado de sua ocorrência isolada, já que estão sempre acompanhadas de outras palavras nos contextos em que figuram. No entanto, conforme afirma Baker (1992: 63), as palavras não se juntam de maneira aleatória umas com as outras, e carregam outros significados ao ocorrerem lado a lado; ou seja, existem padrões linguísticos de uso socialmente acordados a serem seguidos. Ainda segundo a autora, alguns padrões de co-ocorrência de palavras,

TradTerm, São Paulo, v.37, n. 2, janeiro/2021, p. 397-429

Número Especial - Linguística de Corpus

www.revistas.usp.br/tradterm 
que ela denomina collocations ("colocações", em português), podem ser expressos por meio de regras gramaticais (por exemplo, as regências verbal e nominal, "gostar DE", em português, e "like $\varnothing$ ", em inglês), mas podem refletir preferências lexicais de comunidades linguísticas específicas. Estas preferências lexicais não são inerentes a limitações das palavras em si (como, por exemplo, atribuir uma qualidade humana a um ser inanimado: *geladeira chorona), mas escolhas aleatórias e socialmente convencionadas. Por exemplo: dizemos "red wine" no inglês, mas "vinho tinto" no português; "pimenta-do-reino moída na hora" no português brasileiro, mas "pimenta-preta moída na altura", na variante europeia. Para Baker (1992), por sua natureza arbitrária, as colocações são fonte de muitas armadilhas e problemas na tradução, e as Expressões Idiomáticas estão no ponto máximo desse continuum, em termos de fixidez na forma e opacidade no sentido.

Idiomaticidade é o nome que se dá a essa opacidade de sentido observada nas expressões convencionais. Tagnin (2013: 31) define as Els como "expressões semanticamente convencionadas, isto é, expressões cujo significado não pode ser depreendido a partir do significado de suas partes". A autora explica que as Els possuem diferentes graus de idiomaticidade, das menos idiomáticas (contendo um ou alguns elementos idiomáticos, ou expressões metafóricas facilmente decodificáveis, como "brincar com fogo") às totalmente idiomáticas (em que nenhum dos elementos isolados contribui para a decodificação do significado total da expressão, como "marcar touca"). Riva (2009), baseado em outros autores, afirma que tradutores, professores de línguas estrangeiras e lexicógrafos compartilham da convicção de que "o domínio de uma língua passa pelo domínio de suas UFs" (RIvA 2009: 57-58), não só pela fluidez que dão ao discurso, mas porque revelam, também, aspectos culturais (opacos ou não) presentes nas línguas. 0 que nos remete ao conceito de convencionalidade, que engloba tudo aquilo que é consagrado, consolidado pelo uso e aceito de comum acordo por dada comunidade linguística (TAGNIN 2013: 21).

No que diz respeito à tradução de Els, Ortíz Alvarez (2000) observa que é impossível traduzi-las de maneira literal, caso em que seriam recebidas com estranhamento na língua de chegada, pois a combinatória que é idiomática em

TradTerm, São Paulo, v.37, n. 2, janeiro/2021, p. 397-429

Número Especial - Linguística de Corpus

www.revistas.usp.br/tradterm 
uma cultura poderá parecer estranha em outra. Assim, o tradutor encontrará várias dificuldades ao lidar com as Els, pois existem diversos fatores a se considerar no processo de vertê-las para uma outra língua.

Baker (1992), nesse sentido, aponta para o fato de que, antes de se traduzir uma expressão idiomática é preciso interpretar corretamente seu sentido na língua de partida para, então, decidir como traduzi-la para a língua de chegada. A autora sumariza as principais dificuldades envolvidas nesse processo em: a) a expressão pode não ter um equivalente na língua de chegada, pois as línguas têm maneiras diferentes de expressar ideias; b) a expressão pode até ter um equivalente semelhante, mas que é utilizado em contextos diferentes; c) a expressão pode ter sentido literal e idiomático ao mesmo tempo, na língua fonte; d) a frequência de uso de expressões aparentemente equivalentes pode ser diferente em uma língua e na outra. A autora ressalta, ainda, que a questão não é somente usar um equivalente de sentido similar, mas observar também questões de estilo, registro e efeito retórico no contexto imediato e no texto de chegada como um todo (BAKER 1992: 68-72).

Riva (2009) também aponta para a importância do estudo de UFs como as Els, mas foca a importância de se elaborarem materiais de consulta que abordem essas unidades, já que, por apresentarem grande dificuldade, são de suma importância para tradutores, aprendizes e professores de línguas estrangeiras. Tagnin (2013) afirma que a oferta de dicionários de Els para a língua portuguesa é bem menor do que para o inglês. Pode-se depreender daí algumas das dificuldades que tradutores e estudantes de línguas encontram para, primeiramente, reconhecer e compreender as Els em sua própria língua ou em língua estrangeira (por serem, p. ex., de regiões, ou épocas diferentes) e, num segundo momento, para encontrar equivalentes adequados para essas expressões, considerando o contexto de uso e outras restrições micro- e macrotextuais do texto de chegada. Sem entrar no mérito teórico da questão, que é controversa, neste trabalho consideraremos "equivalência" como uma relação de correspondência estabelecida entre dois segmentos ou dois textos produzidos em línguas distintas e considerados como texto de partida e texto de chegada de uma tradução interlingual. Nesse sentido, partilhamos da concepção de tradução como transação, proposta por Pym (1992),

TradTerm, São Paulo, v.37, n. 2, janeiro/2021, p. 397-429 Número Especial - Linguística de Corpus www.revistas.usp.br/tradterm 
para quem a equivalência não pode ser reduzida a um fenômeno estritamente linguístico, pois é uma entidade negociável - e os tradutores são os responsáveis por essa negociação.

Inspiradas pelos autores consultados, em especial Baker e Tagnin, optamos por abordar essa temática utilizando também o aporte metodológico da Linguística de Corpus (doravante LC), que muito tem contribuído para diversas áreas do conhecimento, especialmente para o estudo e a prática da tradução, e para o ensino e a aprendizagem de línguas estrangeiras (Cf., p. ex., VIANA e TAGNIN 2015 e VIANA e TAGNIN 2010). A LC privilegia a observação empírica de textos autênticos organizados sob a forma de corpora eletrônicos (BERBER SARDINHA 2004). Um corpus, segundo Sinclair (2004), é:

[...] uma coleção de fragmentos textuais de língua em formato eletrônico, selecionadas de acordo com critérios externos para representar, tanto quanto possível, uma língua ou variedade linguística como fonte de dados para pesquisas linguísticas ${ }^{2}$.

Para fins desta pesquisa, compilamos um corpus paralelo multiversão que, de acordo com Tagnin, Teixeira e Santos (2009), é aquele que contém textos de partida alinhados com mais de uma versão de sua(s) respectiva(s) tradução(ões). No nosso caso, especificamente, o texto de partida "Pepinos e abobrinhas" (ALEMÃo 2005) foi alinhado, no nível da sentença, com a versão final das traduções feitas por aprendizes do curso PT P $\rightarrow$ I Gerais, conforme detalharemos mais adiante. Esse corpus permitiu, por um lado, observar as diferentes escolhas tradutórias feitas pelos aprendizes ao se depararem com as várias Els nele presentes e, por outro, comparar essas escolhas com as nossas próprias, que se basearam nas sugestões dadas pelos materiais de referência consultados. Toda essa informação foi coletada em uma planilha Excel $\circledast$ e serviu de base para a elaboração de um glossário, consultável online no site do Projeto TermiTraDiCo - Terminologia e Tradução Direcionadas por Corpus $^{3}$. A seguir, descrevemos o procedimento adotado na pesquisa.

2 "[...] a collection of pieces of language text in electronic form, selected according to external criteria to represent, as far as possible, a language or language variety as a source of data for linguistic research." Tradução nossa.

${ }^{3}$ http: / / www.termitradico.unb.br/recursos.

TradTerm, São Paulo, v.37, n. 2, janeiro/2021, p. 397-429

Número Especial - Linguística de Corpus

www.revistas.usp.br/tradterm 


\section{Metodologia}

O primeiro passo para a realização deste trabalho foi fazer um levantamento das Els contidas no texto de partida escolhido (ALEMÃo 2005), organizando os dados

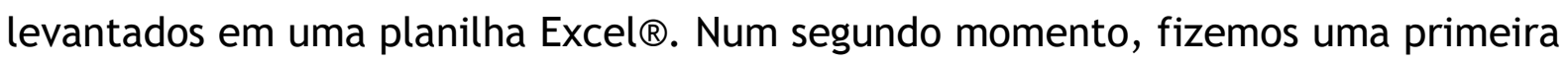
versão do texto para o inglês, tomando nota de todas as informações encontradas nas fontes consultadas durante a tarefa tradutória nessa mesma planilha. Em seguida, compilamos o corpus multiversão de aprendizes, contendo doze versões anonimizadas do mesmo texto para o inglês, feitas por alunos do curso de PT P $\rightarrow$ I Gerais, mais a versão que fizemos após o levantamento de informações para o glossário. A possibilidade de observar as opções utilizadas pelos estudantes ajudounos a produzir uma versão final do texto traduzido, com equivalentes mais próximos ao campo semântico trabalhado. Com base nos dados reunidos nesse percurso, produzimos um material de consulta na forma de um glossário consultável via texto de partida (por meio de hiperlinks) e por busca textual, processo que explicaremos com mais vagar no que se segue.

\subsection{Levantamento das Els do texto de partida e primeira versão para o inglês}

Levando em conta que havíamos previsto a produção de um material de consulta ao final da pesquisa, antes de começar a traduzir, criamos uma planilha para reunir, num banco de dados, as informações que consideramos pertinentes para a elaboração do glossário proposto. Os campos escolhidos para compor esse banco foram:

- Expressão original: expressões levantadas no texto de partida, lematizadas;

- Variações da expressão: variações encontradas nas fontes de referência e na internet para as referidas expressões;

- Definições: informações coletadas em fontes de referência para a compreensão das expressões na língua de partida;

TradTerm, São Paulo, v.37, n. 2, janeiro/2021, p. 397-429

Número Especial - Linguística de Corpus

www. revistas.usp.br/tradterm 
- Expressões de sentido semelhante: expressões equivalentes em sentido, em português, idiomáticas ou não;

- Outras expressões: outras expressões idiomáticas contendo a(s) palavra(s) da El em questão, em português;

- Equivalentes dicionarizados: Els equivalentes coletadas em fontes de referência em inglês (ou outras fontes na internet, quando essas não ofereciam solução);

- Traduções dos alunos: versões das Els propostas pelos alunos de PT P $\rightarrow \mid$ Gerais, idiomáticas ou não, do campo semântico da alimentação ou não, lematizadas e seguidas do número de ocorrências nas traduções, entre parêntesis.

- Nossa(s) proposta(s) de tradução: o equivalente que optamos por utilizar na versão final de nossa tradução; eventualmente indicamos outras boas opções do campo semântico alimentação sugeridas pelos aprendizes.

A ordem em que as Els levantadas foram gravadas na planilha (vide Figura 1) segue a sua ocorrência no texto. As traduções dos estudantes foram acrescentadas à planilha somente após produzirmos nossa versão inicial da tradução para o inglês. Foram utilizados três dicionários disponíveis online para cada língua: o Michaelis, o Priberam e o Dicio, para a língua portuguesa; e o Macmillan, o Cambridge e o Collins, para a língua inglesa. Quando necessário, recorremos também a outros dicionários online de sinônimos e de expressões idiomáticas e a outros materiais disponíveis na rede.

Durante a busca por definições, fomos tomando notas das informações, registrando-as na planilha. Uma vez concluído esse processo, a tradução do texto tornou-se mais fácil. Com as informações coletadas em mãos, produzimos uma primeira versão para o inglês (vide coluna 2 do Apêndice I).

0 passo seguinte foi compilar o corpus paralelo multiversão com as traduções feitas pelos estudantes de PT P $\rightarrow$ I Gerais, para que pudéssemos fazer o levantamento e coleta das soluções (acertadas ou não) apontadas por eles e, em seguida, produzir uma segunda versão do texto em inglês, aproveitando os dados levantados, quando pertinente.

TradTerm, São Paulo, v.37, n. 2, janeiro/2021, p. 397-429

Número Especial - Linguística de Corpus

www.revistas.usp.br/tradterm 
Figura 1: Excerto do banco de dados utilizado para a elaboração do glossário.

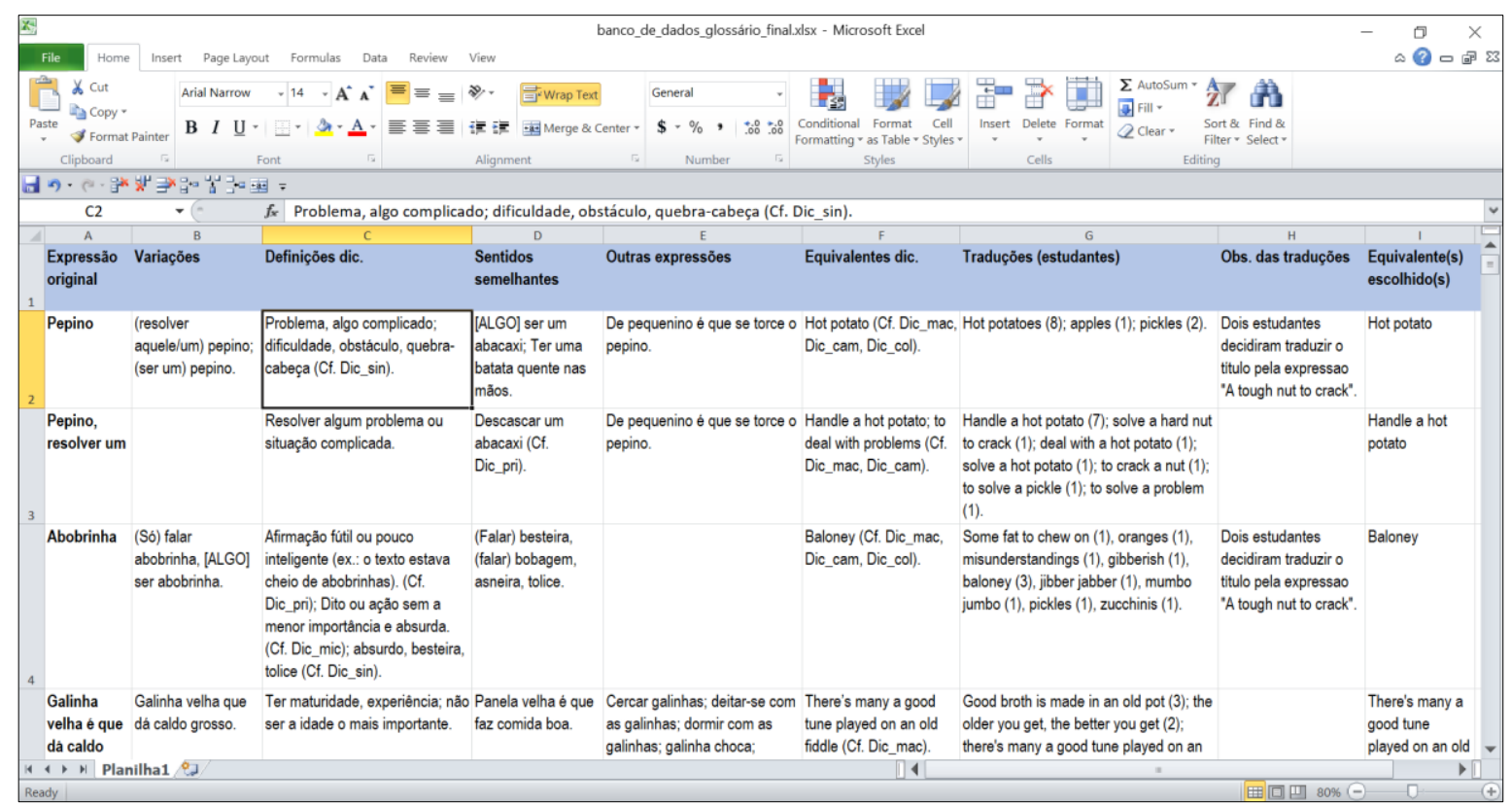

Fonte: as autoras.

\subsection{O corpus paralelo multiversão de aprendizes}

Para a compilação do corpus, coletamos treze versões do texto (ALEMÃo 2005) em inglês, sendo doze feitas por alunos de PT P $\rightarrow$ I Gerais e mais uma, que foi a versão inicial que fizemos do original. As traduções foram alinhadas no nível da sentença, numa planilha Excel ${ }^{\circledR}$, como ilustra a Figura 2.

Em seguida, para que fosse possível explorar os textos com o software de análise linguística AntConc (ANTHONy 2018), cada coluna da planilha foi transformada em um arquivo no formato "texto sem formatação" (.txt) utilizando a seguinte rotina4:

1. Copiar a área contendo o texto traduzido $(\mathrm{Ctrl}+\mathrm{C})$ na planilha;

2. Colar $(\mathrm{Ctrl}+\mathrm{V})$ num arquivo em branco do Word;

3. Acrescentar uma coluna de cada lado da coluna que contém o texto;

4. Na coluna da esquerda, colocar a etiqueta <tit> para o título e uma etiqueta para cada linha subsequente com a máscara: <s[NÚMERO DA LINHA]>. Por

\footnotetext{
${ }^{4}$ Para compreender melhor a utilidade e o funcionamento da etiquetagem em Linguística de Corpus, vide, por exemplo, Teixeira (2007).
}

TradTerm, São Paulo, v.37, n. 2, janeiro/2021, p. 397-429

Número Especial - Linguística de Corpus

www.revistas.usp.br/tradterm 
exemplo, "<s01>" para a linha um e <s30> para a linha 30;

5. Copiar essa coluna preenchida e colar na coluna vazia da direita;

6. Iluminar a coluna da direita e fazer uma substituição em massa de "<” por “</" - a linha 1 ficará com a etiqueta "</s01>" na coluna da direita;

7. Salvar o arquivo como “modelo". Por exemplo: modelo_colunas.docx

8. Iluminar a tabela e converter para texto (Vide Figura 3);

9. Fazer uma substituição em massa de todas as marcas de tabulação $\left({ }^{\wedge} t\right)$ por um espaço em branco (pressione uma vez a barra de espaços no campo indicado, como mostra a Figura 4);

10. Salvar uma versão do arquivo em formato (.txt) (Somente texto / Texto sem formatação), com o nome da coluna em questão. Por exemplo, A01.txt para a tradução do Aluno 1;

11. Voltar ao arquivo "modelo", apagar a coluna do meio (com a tradução já salva) e colar a coluna da próxima tradução da planilha;

12. Repetir os passos 1 a 11 até finalizar todas as colunas.

Figura 2: Excerto do corpus paralelo multiversão de aprendizes de tradução.

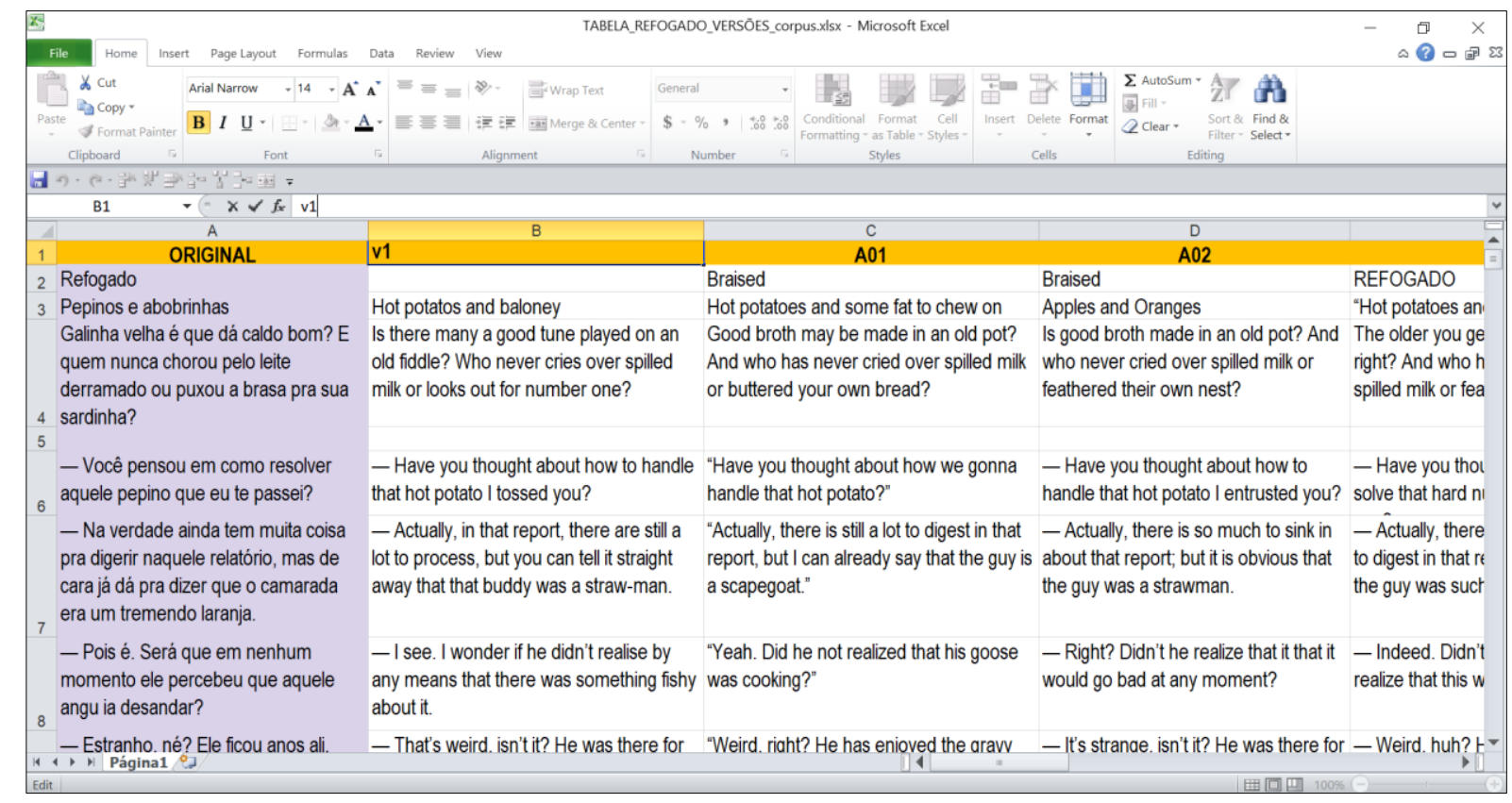

Fonte: as autoras.

TradTerm, São Paulo, v.37, n. 2, janeiro/2021, p. 397-429

Número Especial - Linguística de Corpus

www.revistas.usp.br/tradterm 
Figura 3: Tabela iluminada para ser convertida em texto.

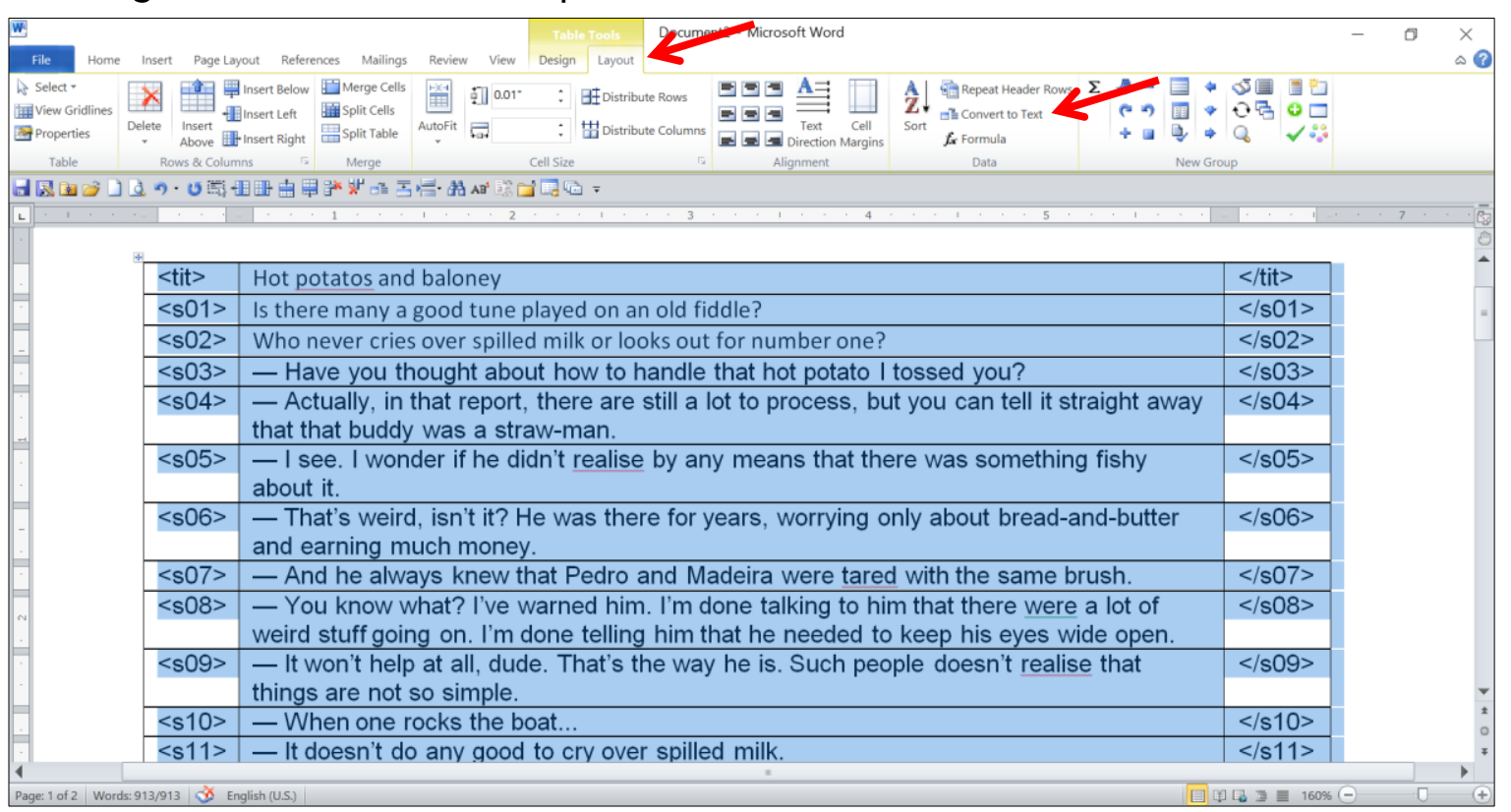

Fonte: as autoras.

Figura 4: Substituição em massa de todas as marcas de tabulação.

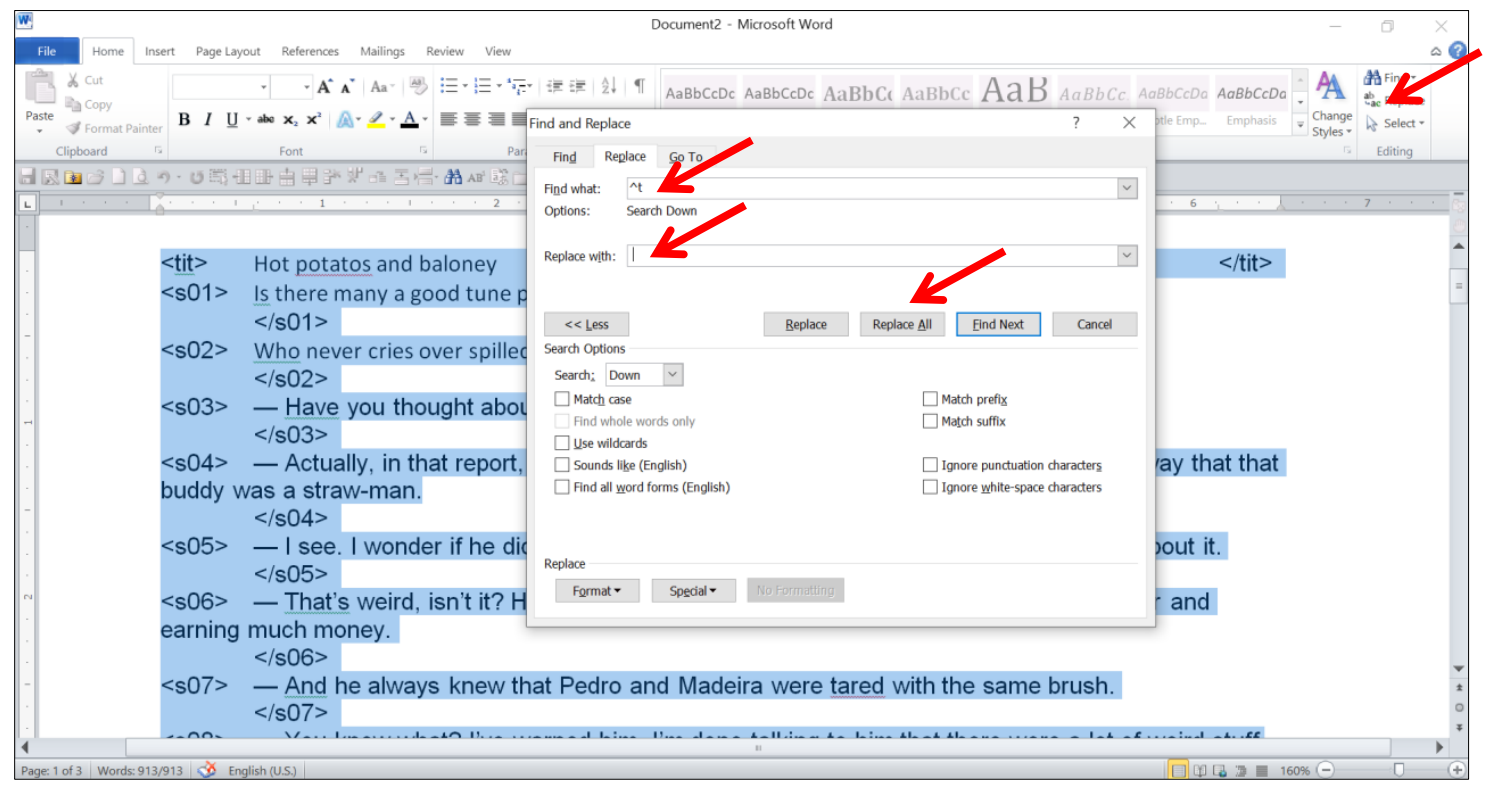

Fonte: as autoras.

Uma vez etiquetados os arquivos no nível da sentença, foi possível visualizar as escolhas feitas pelos alunos simultaneamente, pesquisando as etiquetas criadas como palavra de busca na ferramenta Concordance do programa AntConc (ANTHONY 2018), como é possível observar na Figura 5.

TradTerm, São Paulo, v.37, n. 2, janeiro/2021, p. 397-429

Número Especial - Linguística de Corpus

www.revistas.usp.br/tradterm 
Figura 5: Visualização da sentença <s07> na ferramenta Concordance, AntConc.

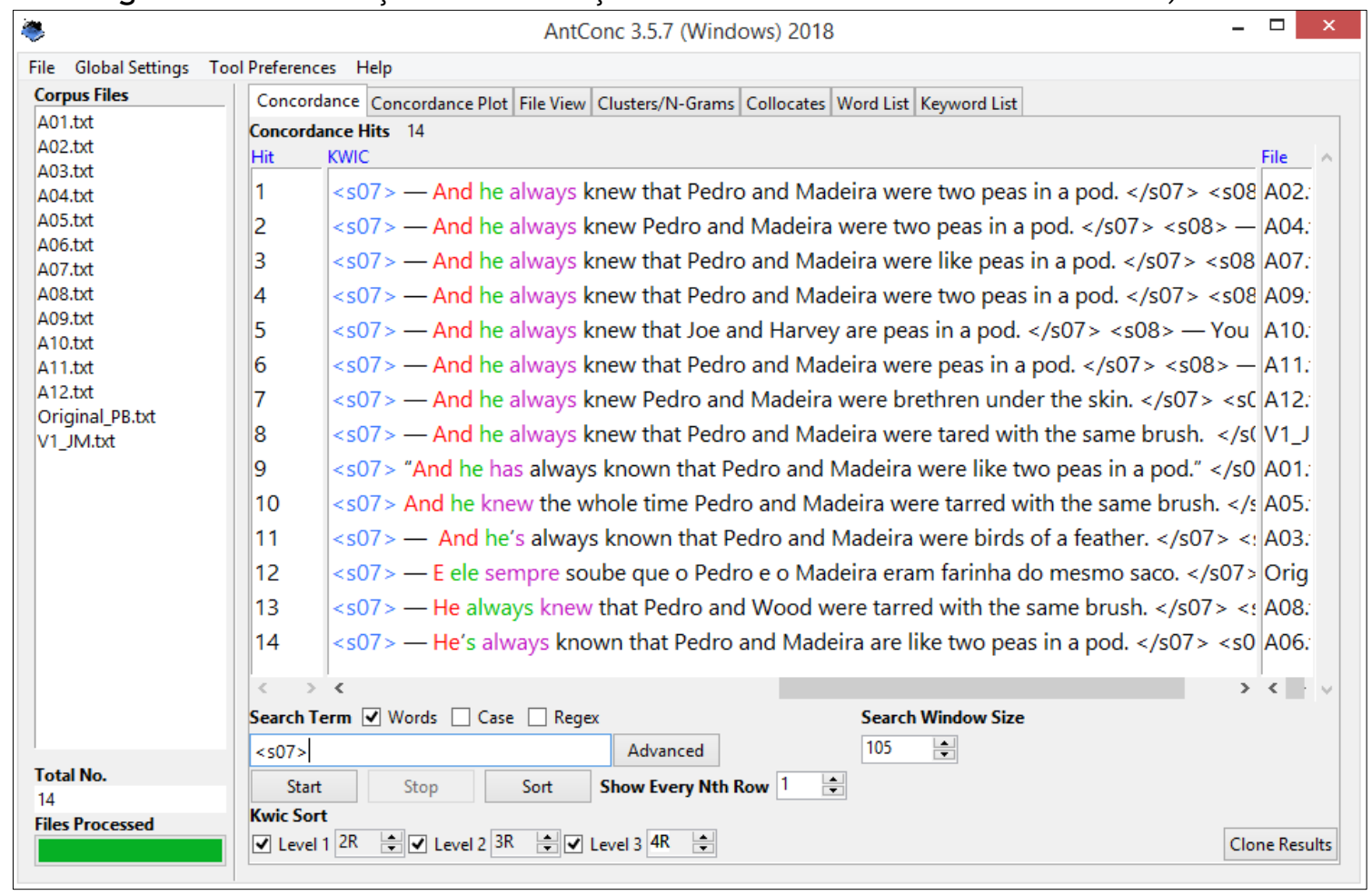

Fonte: as autoras.

\subsection{Elaboração das fichas do glossário}

Como explicado no tópico 4.1, as informações coletadas durante a primeira tradução para a elaboração do glossário foram registradas em uma planilha Excel $\circledast$, bem como os dados levantados na exploração do corpus de aprendizes. Com base nessa planilha, criamos uma "Mala Direta" no Word® para gerar as "fichas" eletrônicas dos verbetes do glossário. Essa ferramenta coleta as informações de uma planilha e as organiza num arquivo de texto, de acordo com uma estrutura previamente determinada pelo usuário. A "Mala Direta" costuma ser usada para preencher etiquetas de endereçamento e diplomas, por exemplo, em que há um texto fixo e campos que vão variar (como o nome e o endereço) - caso em que os dados são puxados de uma planilha vinculada. Para fazer isso, seguimos a seguinte rotina: 
1. Abrir um arquivo em branco do Word®;

2. Abrir a aba de Mala Direta (Mailing, em inglês);

3. Clicar em "Selecionar Destinatários" (Select recipients, em inglês) e, na lista que se abre, escolher "Usar uma Lista Existente" (Use existing list, em inglês);

4. Procurar, no computador, a planilha contendo o banco de dados que servirá de base para a criação dos documentos;

5. Na janela pop-up que se abre, marcar (ou não) a opção que considera a primeira linha de sua planilha / banco de dados como uma linha de nomeação das colunas (se for o caso) e clicar em OK;

6. Clicar no botão "Gravar e Inserir Campos" (Insert Merge Field, em inglês) e selecionar os campos a serem exibidos em cada "ficha", formatando-os da maneira que preferir (com negrito, cores diferentes, itálico, sublinhado, cor de fundo etc. Vide Figura 6);

7. Salvar como "modelo". Por exemplo: gloss_modelo.docx;

8. Clicar no botão "Concluir e Mesclar" (Finish \& Merge, em inglês) e, na janela que se abre, escolher a primeira opção, "Editar Documentos Individuais" (Edit Individual Documents) e, em seguida, "Todos" (All);

9. Salvar com um novo nome. Por exemplo: gloss_entradas.docx.

Para fazer alterações no modo de exibição dos campos, reabra o arquivo "modelo" e, depois de feitas as alterações, repita os passos 8 e 9.

Figura 6: Seleção e formatação dos campos a serem exibidos nos “verbetes”.

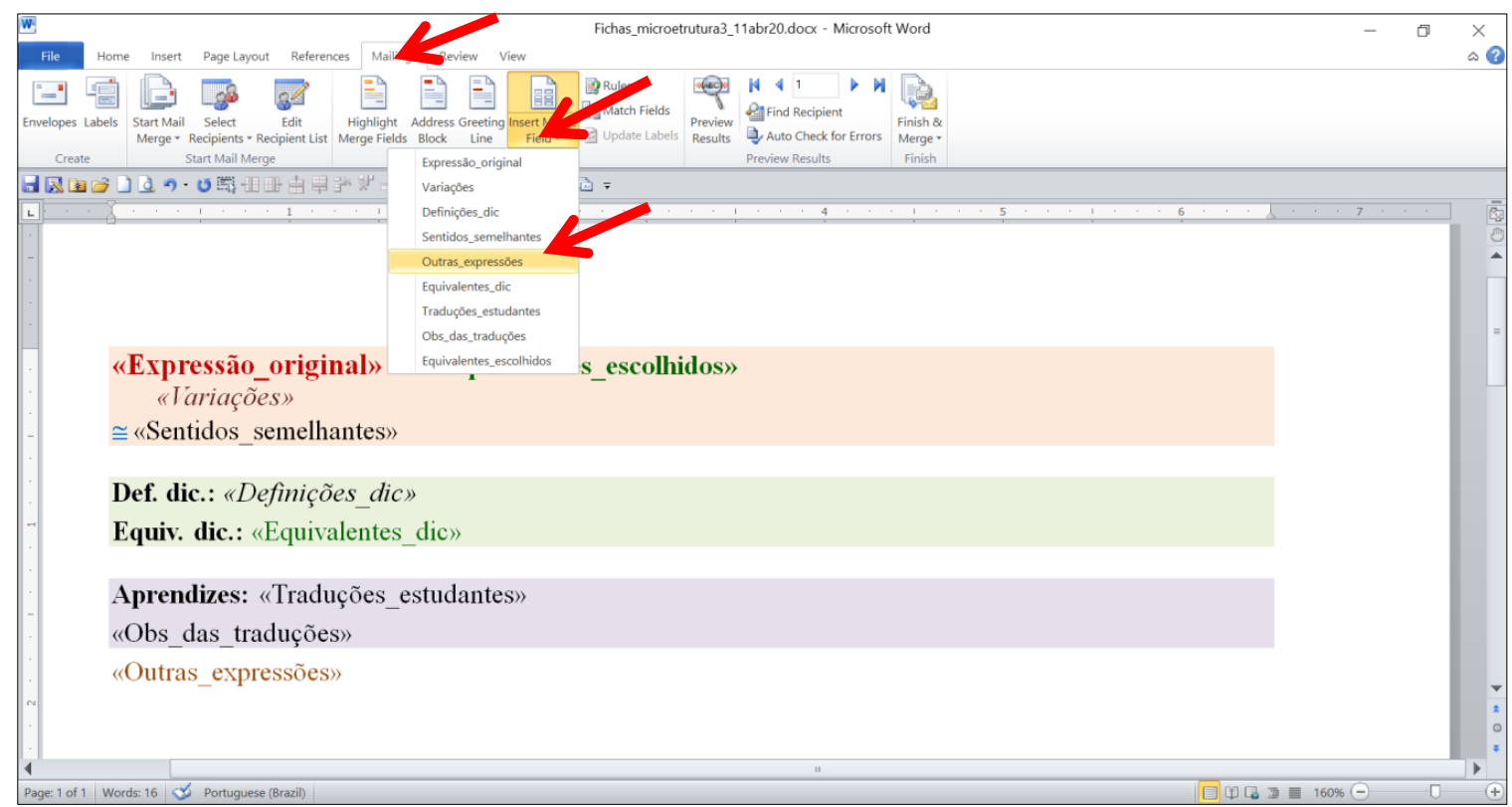

Fonte: as autoras.

TradTerm, São Paulo, v.37, n. 2, janeiro/2021, p. 397-429

Número Especial - Linguística de Corpus

www.revistas.usp.br/tradterm 
O local onde estão os campos serão substituídos pelo respectivo dado proveniente da planilha, respeitando a formatação indicada. Tudo o que estiver fora dos campos (indicados pelos delimitadores “«” e “»”) aparecerá em cada uma das "fichas" geradas.

Dessa forma, os dados de cada linha da planilha foram transformados em verbetes e salvos como arquivos distintos, seguindo sua numeração de aparição no texto de partida; p. ex.: V01_pepino.docx. Por fim, utilizando o sistema de acréscimo de hyperlinks, conectamos cada um dos arquivos gerados à sua respectiva El no texto de partida, para que pudessem ser facilmente consultados quando da leitura do original. Disponível no site do Grupo de Pesquisa TermiTraDiCo, na aba de Recursos (http://www.termitradico.unb.br/recursos), o glossário pode ser usado como material didático e/ou recurso de consulta. Para consultar as Els do glossário basta clicar com o mouse posicionado sobre a expressão desejada e o verbete se abrirá na tela, na forma de uma janela pop-up (vide Figura 7).

Figura 7: consulta de Els do texto original através de hyperlinks.

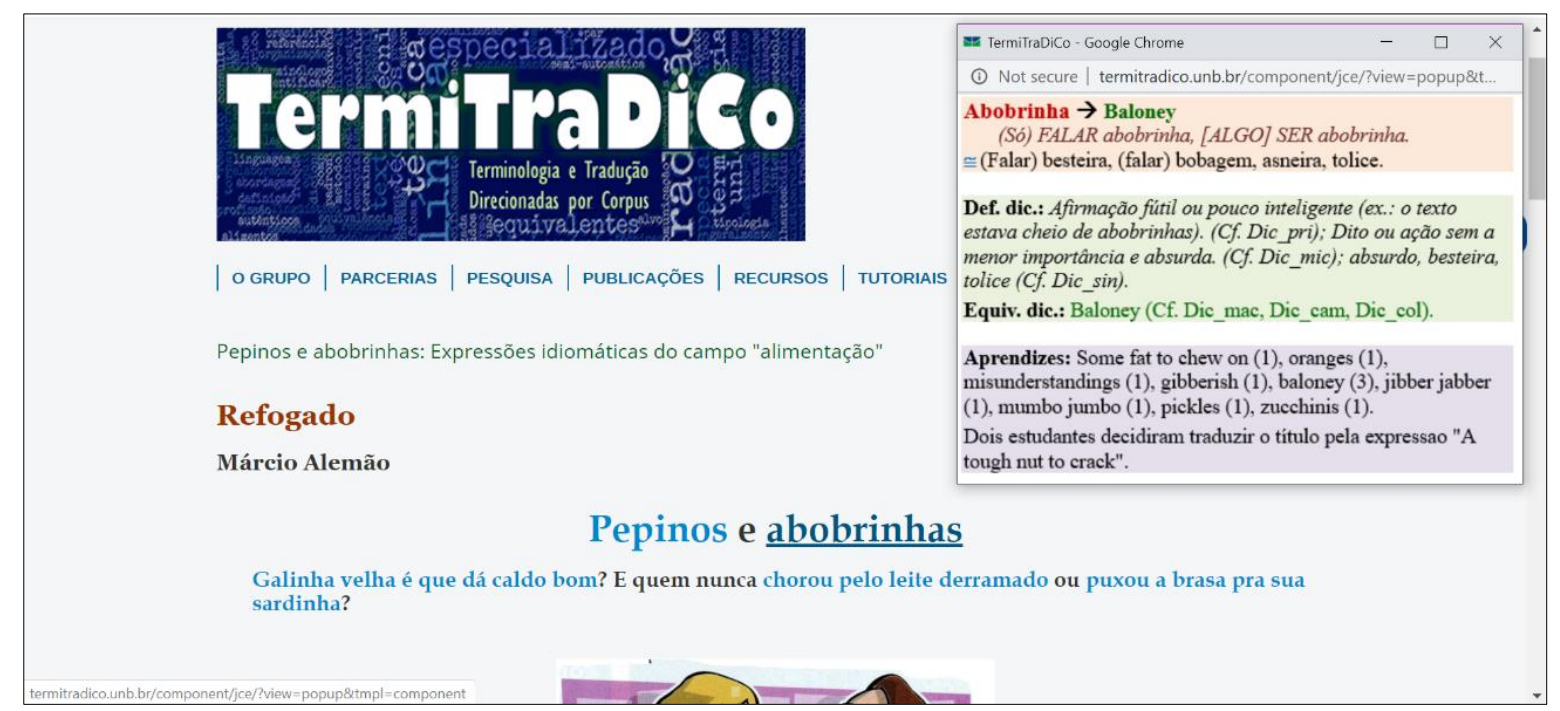

Fonte: as autoras.

TradTerm, São Paulo, v.37, n. 2, janeiro/2021, p. 397-429

Número Especial - Linguística de Corpus

www.revistas.usp.br/tradterm 


\section{Resultados}

O levantamento de Els no texto de partida rendeu 48 entradas, para as quais pesquisamos definições nos dicionários mencionados anteriormente, registrando os dados da pesquisa num banco de dados. Buscamos pelas palavras presentes nas Els nas fontes de consulta e, dentre as utilizadas para o português, percebemos que 0 dicionário online Michaelis foi o que mais disponibilizou Els. Além das definições para as palavras procuradas, essa obra traz, separadamente, uma lista de expressões em que a palavra em questão figura, acompanhadas de suas respectivas definições. O dicionário Priberam também se mostrou bastante útil, com listas de expressões contendo a palavra buscada e permitindo, inclusive, buscas na variante europeia do português. O dicionário Dicio foi útil para a busca de algumas informações, apesar de não disponibilizar tantas expressões como os outros dois, e de não disponibilizá-las separadamente, o que dificultou a visualização.

Ao longo da coleta, observamos que foi mais difícil encontrar definições para $24(50 \%)$ das 48 expressões pesquisadas nas fontes de pesquisa utilizadas (Quadro 1).

Quadro 1: Els identificadas no texto de partida não encontradas nos dicionários pesquisados.

\begin{tabular}{|l|l|}
\hline 1 & "galinha velha é que dá caldo bom" \\
\hline 2 & "angu DESANDAR" \\
\hline 3 & "FICAR com um olho no peixe e outro no gato" \\
\hline 4 & "rapadura é doce, mas não é mole(, não)" \\
\hline 5 & "MUDAR de pato pra ganso" \\
\hline 6 & "quem tem pressa come cru" \\
\hline 7 & "colocar [ALGUÉM] na geladeira" \\
\hline 8 & "(QUERER) assobiar e chupar cana (ao mesmo tempo)" \\
\hline 9 & "[ALGUÉM/ALGUMA COISA] DAR algum caldo" \\
\hline 10 & "(Com qual) fatia do bolo ([ALGUÉM] (IR) FICAR)" \\
\hline 11 & "SENTAR no pudim" \\
\hline 12 & "SER gato de cozinheira" \\
\hline 13 & "SUAR mais que pano de cuscuz" \\
\hline 14 & "[ALGUÉM] SER um biscoitão" \\
\hline 15 & "([ALGUÉM] TER seus) dias de glória" \\
\hline 16 & "[ALGUÉM] VIRAR / ESTAR / SER um bagaço" \\
\hline 17 & "COMER (o mingau) pelas beiradas" \\
\hline 18 & "é no fogo baixo que o feijão engrossa" \\
\hline
\end{tabular}

TradTerm, São Paulo, v.37, n. 2, janeiro/2021, p. 397-429 Número Especial - Linguística de Corpus www.revistas.usp.br/tradterm 


\begin{tabular}{|l|l|}
\hline 19 & "REQUENTAR uma história" \\
\hline 20 & "[ALGO] SER um peru no pires" \\
\hline 21 & "ASSAR manteiga no espeto" \\
\hline 22 & "FRITAR [ALGUÉM]" \\
\hline 23 & $\begin{array}{l}\text { "[ALGUÉM] só VER as pingas que [ALGUÉM] BEBER/TOMAR, } \\
\text { mas não ver os tombos que [ALGUÉM] LEVAR" }\end{array}$ \\
\hline 24 & "em casa onde não tem pão, todo mundo grita" \\
\hline
\end{tabular}

Fonte: as autoras.

Para as expressões não encontradas, foi necessária a pesquisa de definições em outras fontes de consulta disponíveis online, como, por exemplo, o texto "Tudo termina em pizza” (FUKELMANN 2000), e o e-book Termos e expressões do coloquial do cotidiano da zona rural no Brasil central no século XX (NogUeIRA E SILVA 2017). Por exemplo: não encontramos nenhum equivalente idiomático satisfatório para "ficar com um olho no peixe e o outro no gato", traduzida por nós, na versão final, como “keep his eyes wide open”. Mas, adotando a estratégia de compensação, que consiste em tentar recuperar um recurso idiomático do texto de partida em outro ponto do texto de chegada (BAKER 1992: 78), traduzimos o trecho "tinha muita coisa esquisita rolando", que ocorre na mesma fala do texto de partida, mas na sentença anterior, por "there was something fishy going on”, acrescentando, assim, uma El que não estava presente no texto de partida naquele trecho específico, como uma forma de recuperar o efeito idiomático perdido na expressão da sentença seguinte.

Foi interessante notar que, ao buscar expressões que continham palavras em comum com as Els pesquisadas, algumas renderam muito mais Els adicionais que outras. Dentre elas, as mais produtivas foram “mão” (54 Els), “gato” (21), "fogo” (20), “olho” (19), “pedra” (16) e “galinha” (11). Esse dado parece sugerir uma tendência para a criação de expressões idiomáticas com estes campos semânticos - partes do corpo humano, fenômeno da natureza e animais -, além do já suscitado campo da alimentação, inspiração do nosso texto de partida. É possível que essas escolhas sejam culturalmente marcadas e variem de uma língua a outra, ou mesmo de uma variante linguística ou regional a outra. Mas isso é algo que não podemos afirmar sem uma investigação mais aprofundada.

TradTerm, São Paulo, v.37, n. 2, janeiro/2021, p. 397-429

Número Especial - Linguística de Corpus

www. revistas.usp.br/tradterm 
Para a localização de Els em inglês, utilizamos primeiramente a ferramenta de busca Google para encontrar possíveis equivalentes em fóruns, como, por exemplo, o English Experts ${ }^{5}$ e, em seguida, fomos em busca dessas expressões nos dicionários MacMillan, Cambridge e Collins. Assim como nas fontes de referência em português, alguns dicionários apresentaram mais Els do que outros para as palavras pesquisadas, sendo o Macmillan o que mais resultados apresentou, seguido do Cambridge e, por último, do Collins. Os dados também foram anotados na planilha do banco de dados. Após essa etapa, fizemos uma primeira versão do texto de partida para o inglês e, em seguida, partimos para a análise do corpus multiversão.

Ao observar as traduções dos estudantes, percebemos que houve pouca variação na tradução de sentenças não idiomáticas, como "gostei da secretária dele", traduzida por “I liked his secretary" por 10 dos 13 estudantes e por “I like his secretary" pelos outros 3. Já para as Els mais idiomáticas, como "é no fogo baixo que o feijão engrossa" e "assar manteiga no espeto", cada aluno traduziu de maneira diferente, e não necessariamente por equivalentes idiomáticos, ou da temática alimentação, como pode ser observado nas capturas de tela das Figuras 8 e 9. Por outro lado, a única El para a qual houve escolha unânime de equivalente foi “CHORAR (sobre o / pelo) leite derramado", traduzida por todos por "TO CRY over spilled milk", apesar de três alunos terem optado pela utilização de "spilt milk" (variante britânica) e outros dois terem cometido erro ortográfico "split milk”, como pode ser visto na Figura 10. Outras expressões que tiveram escolhas semelhantes entre os alunos podem ser vistas no Quadro 2.

Quadro 2: Algumas Els com escolhas semelhantes entre os alunos.

\begin{tabular}{|c|c|c|}
\hline Expressão na LP & Equivalente escolhido & $\begin{array}{l}\text { No de } \\
\text { alunos }\end{array}$ \\
\hline Colocar a mão na massa & To get one's hand(s) dirty & 10 \\
\hline SER osso duro de roer & TO BE a hard/tough nut to crack & 9 \\
\hline $\begin{array}{l}\text { ASSOBIAR e CHUPAR cana (ao } \\
\text { mesmo tempo) }\end{array}$ & Have your cake and eat it (too) & 8 \\
\hline FICAR de molho (em casa) & (TO BE on) bed rest & 8 \\
\hline RESOLVER um pepino & TO HANDLE a hot potato & 7 \\
\hline
\end{tabular}

Fonte: as autoras.

${ }^{5}$ Disponível em: https://www.englishexperts.com.br/forum/. Acesso em novembro de 2019.

TradTerm, São Paulo, v.37, n. 2, janeiro/2021, p. 397-429

Número Especial - Linguística de Corpus

www.revistas.usp.br/tradterm 
Figura 8: Traduções da expressão "é no fogo baixo que o feijão engrossa".

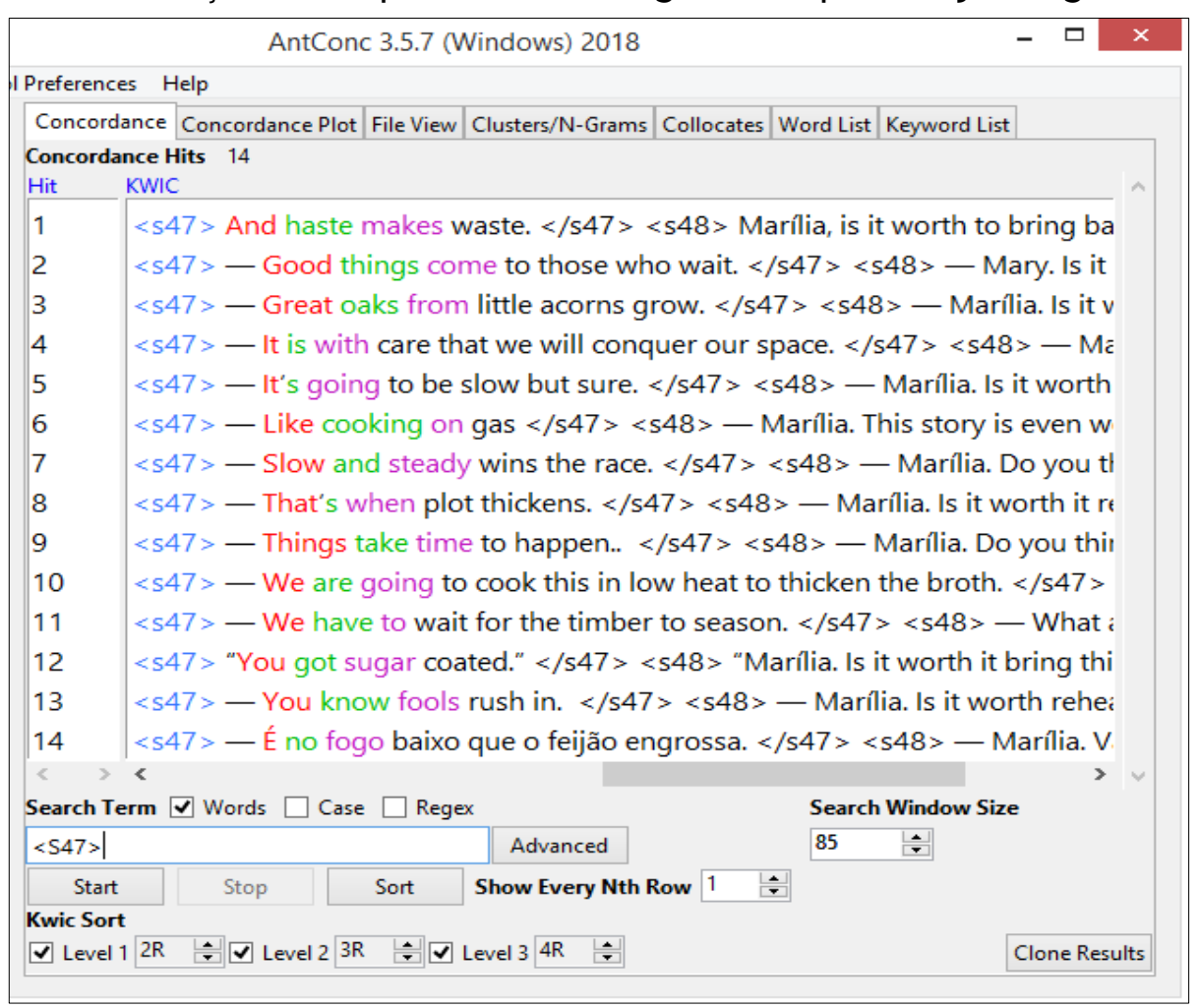

Fonte: as autoras.

Figura 9: Traduções da expressão "assar manteiga no espeto".

\begin{tabular}{|c|c|c|c|c|c|c|c|c|c|}
\hline & & & & ntConc 3.5.7 (Wi & indows) 20 & 018 & & $-\square$ & $x$ \\
\hline Preferences & $\mathrm{He}$ & & & & & & & & \\
\hline Concordan & & Concordance Plot & t File View & Clusters/N-Grams & Collocates & Word List & Keyword List & & \\
\hline Concordanc & ce $\mathrm{Hi}$ & its 14 & & & & & & & \\
\hline Hit & WWIC & & & & & & & & $\wedge$ \\
\hline 1 & $<\mathrm{s} 5$ & $7>-$ And as & my granc & dmother would & say: havi & ing too $\mathrm{m}$ & nuch is like & and. $</ \mathrm{s}^{\mathrm{r}}$ & \\
\hline 2 & $<\mathrm{s} 5$ & 7> "And how & has mon & hey to burn, as g & grandma & used to s & say, pours & $s 58>" D$ & \\
\hline 3 & $<\mathrm{s} 5$ & $7>-$ And if $y$ & you are to & oo greedy, my g & grandmot & ther used & to say, you & \rangle$\langle s 58\rangle$ & \\
\hline 4 & $<s 5$ & $7>-$ And lik & e my grar & ndma's used to & say, one & can alwa & ays get thei & $58>-[$ & \\
\hline 5 & $<\mathrm{s} 5$ & $7>-$ And $m$ & y grandm & ha said: don't pu & ut all your & r eggs in & one baske & you hearı & \\
\hline 6 & $<\mathrm{s} 5$ & $7>-$ And the & ose who r & have too much, & as my gr & randma u & used to say & $<1$ & \\
\hline 7 & $<\mathrm{s} 5$ & $7>-$ And $w h$ & ho has a lc & lot, said my grar & ndmother & r, can get & t blood out & - Did & \\
\hline 8 & $<\mathrm{s} 5$ & $7>-$ And $w h$ & hoever ha & as too much, use & ed to say & my granc & dma, usual & with his $\mathrm{r}$ & \\
\hline 9 & $<\mathrm{s} 5$ & $7>-$ And $w h$ & hoever ha & as much, my gra & andmothe & er would & say, fritter & Did you $h$ & \\
\hline 10 & $<\mathrm{s} 5$ & $7>-$ As my & grandma & used to say, on & he who ha & as too $\mathrm{mu}$ & uch money & $s 57><s !$ & \\
\hline 11 & $<\mathrm{s} 5$ & 7> As my gra & ndmothe & er used to say, ri & ich people & e tend to & fritter thin & Have you & \\
\hline 12 & $<\mathrm{s} 5$ & $7>-E$ quen & tem mui & ito, dizia minha & avó, assa & manteig & ga no espet & sabend & \\
\hline 13 & $<\mathrm{s} 5$ & $7>-$ My gra & ndma use & ed to say that w & whoever $\mathrm{h}$ & las too $\mathrm{m}$ & nuch do un & \rangle$\langle s 58\rangle$ & \\
\hline 14 & $<s 5$ & $7>-$ My gra & indmothe & r used to say th & hat those & who have & e a lot, ofte & - Did you & \\
\hline$<><$ & & & & & & & & $>$ & $\checkmark$ \\
\hline Search Tern & $m \sqrt{ }$ & 1 Words $\square$ Cas & e $\square$ Regex & & & Search 1 & Window Size & & \\
\hline$\langle s 57\rangle$ & & & & Advanced & & 115 & $\div$ & & \\
\hline Start & & Stop & Sort & Show Every Nth R & low 1 & & & & \\
\hline Kwic Sort & & & & & & & & & \\
\hline$\checkmark$ Level $1 \longdiv { 2 }$ & $2 R$ & $\because \nabla$ Level 2 & $\div \nabla L$ & Level $3 \longdiv { 4 R }$ & & & & Clone ResL & \\
\hline
\end{tabular}

Fonte: as autoras.

TradTerm, São Paulo, v.37, n. 2, janeiro/2021, p. 397-429

Número Especial - Linguística de Corpus

www.revistas.usp.br/tradterm 
Figura 10: Traduções da expressão "chorou pelo leite derramado".

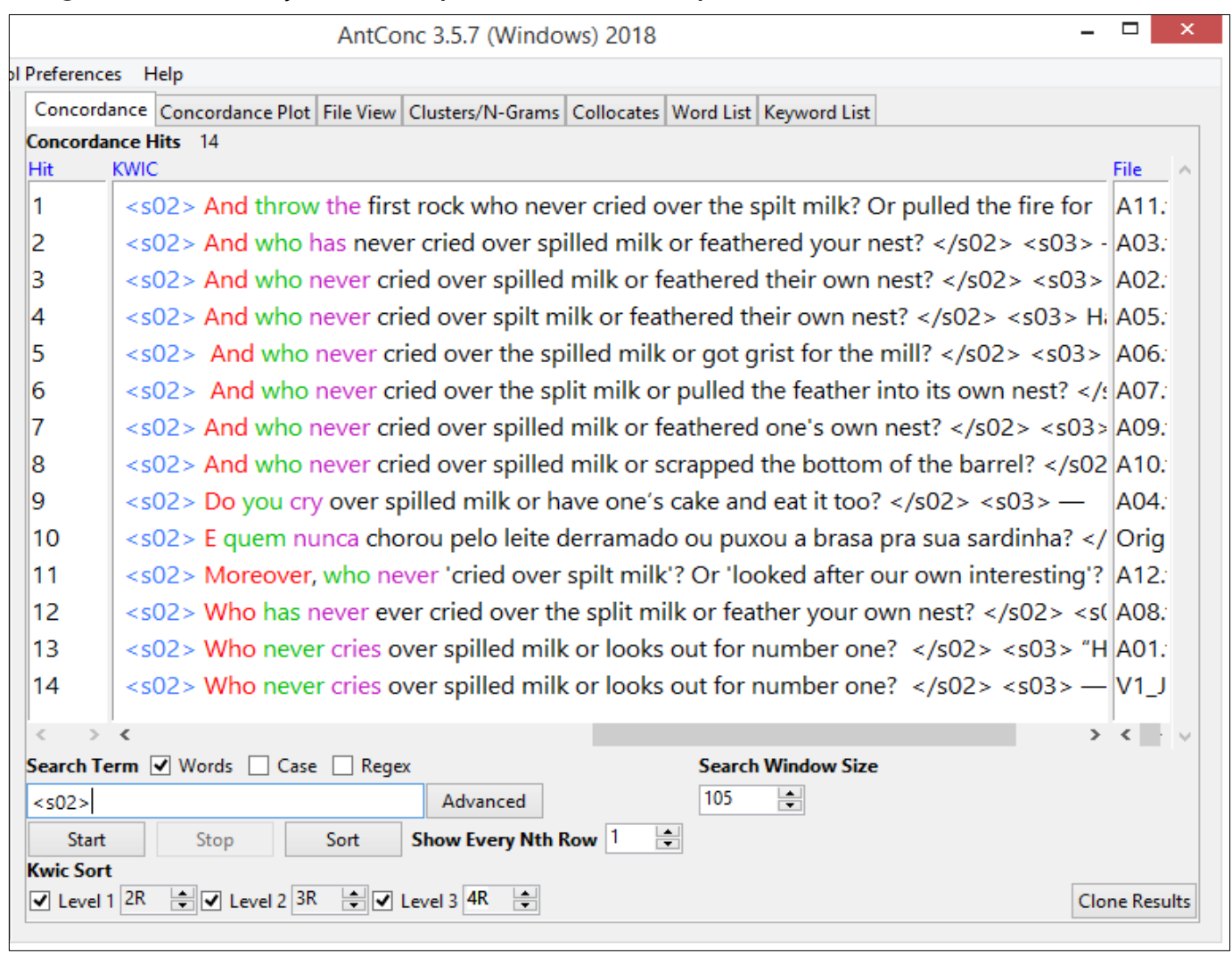

Fonte: as autoras.

Nossa segunda versão do texto, feita após a exploração do corpus, foi bastante influenciada pelas escolhas dos alunos, pois possibilitou a identificação de alternativas mais adequadas, antes não pensadas ou encontradas nas fontes consultadas. Tomemos como exemplo a expressão "SER farinha do mesmo saco", que em nossa primeira versão optamos por traduzir como "tared with the same brush". Apesar de ter sentido e prosódia semântica (negativa) semelhantes, esta El nada tem a ver com o campo semântico da alimentação; por isso, em nossa segunda versão optamos por "TO BE two peas in a pod" (literalmente "SER duas ervilhas em uma vagem”), que tem prosódia semântica diferente (neutra), porém com sentido semelhante, além de conter elementos do campo semântico trabalhado. Outro exemplo foi a mudança de equivalente para a expressão "mudar de pato pra ganso", que inicialmente traduzimos por "changing the subject" (de sentido semelhante, mas nada idiomático) e, na segunda versão, por “MOVE on from chalk to cheese". Em suma, a possibilidade de explorar um corpus paralelo multiversão de aprendizes ajudou muitíssimo na tarefa de encontrar e selecionar equivalentes mais idiomáticos dentro do campo semântico trabalhado.

TradTerm, São Paulo, v.37, n. 2, janeiro/2021, p. 397-429

Número Especial - Linguística de Corpus

www.revistas.usp.br/tradterm 


\section{Considerações finais}

As Els apresentam diversas dificuldades para os aprendizes e profissionais que trabalham com línguas, conforme argumentamos na parte inicial deste trabalho. Partindo dessa premissa, buscamos fazer um levantamento e estudo sistemático e contrastivo de algumas delas a partir de um texto, em português brasileiro, elaborado em torno de cerca de cinquenta Els do campo semântico da alimentação. No percurso de sua tradução para o inglês, observamos e vivenciamos os possíveis percalços enfrentados por estudantes de tradução e de línguas estrangeiras ao tentar traduzir essas Els para o inglês.

A tarefa se mostrou "uma faca de dois gumes", pois, apesar de ter sido divertido trabalhar com essas Els, enfrentamos diversos obstáculos na busca por soluções tradutórias para o inglês, especialmente pela dificuldade em encontrar definições na língua de partida e equivalentes na língua de chegada em um campo semântico tão restrito - características impostas pelas configurações micro- e macrotextuais do texto de partida. Isso nos fez refletir sobre a necessidade de se criarem outros formatos para registro e consulta das expressões idiomáticas e de possíveis equivalentes numa segunda língua - talvez uma obra organizada por campos semânticos, conforme sugere Riva (2009), teria facilitado nosso trabalho? Mas, para responder esta pergunta, teríamos que ampliar nosso escopo de pesquisa e, de fato, testar comparativamente a eficácia de um material assim organizado com o que há disponível atualmente.

O uso do corpus, por sua vez, demonstrou novamente ser de grande utilidade no apoio à tarefa tradutória, como já demonstrado, entre muitos outros autores, por Viana e Tagnin (2015). Por meio do corpus paralelo multiversão de aprendizes de tradução que compilamos, foi possível observar diversas possibilidades para se verter as Els de uma língua à outra. Muitas foram as soluções encontradas pelos estudantes, ora buscando equivalentes idiomáticos (do campo semântico trabalhado ou não), ora traduzindo literalmente. Por um lado, observamos pelo menos uma El da língua de partida que possui uma El conhecida e semelhante na língua de chegada, "chorou pelo leite derramado" $\rightarrow$ "to cry over spilled / spilt milk", a única equivalência apontada com unanimidade pelos

TradTerm, São Paulo, v.37, n. 2, janeiro/2021, p. 397-429

Número Especial - Linguística de Corpus

www.revistas.usp.br/tradterm 
aprendizes. No entanto, a maioria das Els apresentou maior dificuldade, tanto na compreensão quanto na tradução, o que pode ser observado pela variedade de equivalentes sugeridos. É o caso, por exemplo, da expressão "assar manteiga no espeto", que foi traduzida de uma forma diferente por cada aluno cujas traduções compõem o corpus (vide Figura 9).

Como bem sumarizou Baker (1992), muitas expressões podem não ter equivalentes na língua de chegada ou, mesmo quando são encontrados equivalentes, é possível que sejam empregados em contextos diferentes nas duas línguas e suas variantes, ou não sejam adequados para o estilo ou a temática do texto trabalhado. Ou seja, para cada caso é preciso considerar as condições de produção e recepção dos textos de partida e de chegada para que se possa selecionar estratégias de tradução (Cf. BAKER 1992: 27-42) - que optamos por não abordar neste trabalho, mas que foram consideradas pelos aprendizes ao traduzir.

Corroboramos, neste trabalho, a hipótese de que compreender, traduzir e utilizar Els é um grande desafio no contexto de aprendizado de uma segunda língua, mais especificamente, no nosso caso, no contexto da tradução. Esperamos que os resultados de nossa pesquisa, além de contribuírem para evidenciar essas dificuldades, sirvam de material de estudo para o aprendizado e a prática de tradutores e aprendizes de português e inglês por meio do material resultante, e que estimulem outros estudos utilizando esta mesma abordagem e/ou temática.

TradTerm, São Paulo, v.37, n. 2, janeiro/2021, p. 397-429 Número Especial - Linguística de Corpus www.revistas.usp.br/tradterm 


\section{Referências}

Alemão, M. Pepinos e abobrinhas. Carta Capital, 337, São Paulo, abr. 2005, p. 60.

ANTHONY, L. AntConc (Version 3.5.7) [Computer Software]. Tokyo, Japan: Waseda University, 2018. Disponível em: http: / /www.laurenceanthony.net/software. Acesso em set 2019.

BAKER, M. In other words: a coursebook on translation. $1^{\circ}$ ed. London and New York: Routledge, 1992.

Berber Sardinha, A.P. Lingüística de Corpus. Barueri: Manole, 2004.

CAMBRIDGE DictionARY. Disponível em: https: / / dictionary.cambridge.org/. Acesso em out. 2019.

Collins Dictionary. Disponível em: https: //www.collinsdictionary.com/. Acesso em out. 2019.

DICIONÁRIO DE EXPRESSÕES IDIOMÁTICAS. Disponível em:

http: //www.deipf.ibilce.unesp.br/pt/index.php. Acesso em out. 2019.

DICIONÁRIO MICHAELIS. Disponível em: http://michaelis.uol.com.br/. Acesso em out. 2019.

DicionÁRIO OnLINE DE PORTUguÊs. Disponível em: https://www.dicio.com.br/. Acesso em out. 2019.

DicionáRIo Priberam da Língua Portuguesa. Disponível em:

https://dicionario.priberam.org/. Acesso em out. 2019.

DICIONÁRIO DE SINÔNIMOS ONLINE. Disponível em: https://www.sinonimos.com.br/. Acesso em out. 2019.

FukeLmanN, M. Tudo termina em pizza. Folha de S.Paulo: Colunas e blogs, 5 maio 2000. Disponível em:

https://www1.folha.uol.com.br/folha/pensata/fukelmann_20000505.htm. Acesso em nov. 2019.

MACMILLAN DictionARY. Disponível em: https://www.macmillandictionary.com/. Acesso em out. 2019.

NogueIRA, I. D.; SIlva, A. H. Termos e expressões do coloquial do cotidiano da zona rural no Brasil central no século XX. Goiânia: Gráfica UFG, 2017. Disponível em: https://www.cegraf.ufg.br/up/688/o/ebook_ismael_armando.pdf. Acesso em nov. 2019.

TradTerm, São Paulo, v.37, n. 2, janeiro/2021, p. 397-429

Número Especial - Linguística de Corpus

www.revistas.usp.br/tradterm 
Ortíz Alvarez, M. L. Expressões idiomáticas do português do Brasil e do espanhol de Cuba: estudo contrastivo e implicações para o ensino do português como língua estrangeira. Tese (Doutorado) - Instituto de Estudos da Linguagem, Universidade Estadual de Campinas, Campinas, 2000.

Pym, A. The Relations between Translation and Material Text Transfer. Target 4:2, 1992.

RIVA, H. C. Dicionário onomasiológico de expressões idiomáticas usuais na língua portuguesa no Brasil. Tese (Doutorado) - Universidade Estadual Paulista, Instituto de Biociências, Letras e Ciências Exatas, 2009. Disponível em: http: //hdl.handle.net/11449/100104. Acesso em ago. 2019.

SINCLAIR, J. Corpus and Text - basic principles. Developing Linguistic Corpora: a guide to good practice. 2004. Disponível em http: //users.ox.ac.uk/ martinw/dlc/chapter1.htm. Acesso em: jul. 2019.

TAGNIN, S. E. O. O jeito que a gente diz: expressões convencionais e idiomáticas. Barueri: DISAL, 2013.

TAGNIN, S. E.O.; TEIXEIRA, E. D.; SANTOS, D. CorTrad: A multiversion translation corpus for the Portuguese-English pair. Arena Romanistica 4, 2009, pp. 314-323.

TEIXEIRA, E. D. Etiquetagem em Lingüística de Corpus: possibilidades de aplicação. In: GERBER, R. M.; VASILÉVSKI, V. (Eds.). Um percurso para pesquisas com base em corpus. Florianopolis: EDUFSC, 2007, pp. 116-148.

VIANA, V.; TAGnin, S. E. O. (Orgs.). Corpora na tradução. São Paulo: HUB Editorial, 2015.

VIANA, V.; TAGNIN, S. E. O. (Orgs.). Corpora no ensino de línguas estrangeiras. São Paulo: HUB Editorial, 2010.

Xatara, C.; Riva, H. C.; Rıos, T. H. C. Tradução de idiomatismos. Cadernos de Tradução, v. 2, n. 8, Florianópolis, jan. 2001, pp. 183-194. Disponível em: https: //periodicos.ufsc.br/index.php/traducao/article/view/5892/5572. Acesso em nov. 2019. doi: https://doi.org/10.5007/\%x.

Recebido em: 25/04/2020

Aceito em: 22/09/2020

Publicado em janeiro de 2021

TradTerm, São Paulo, v.37, n. 2, janeiro/2021, p. 397-429

Número Especial - Linguística de Corpus

www.revistas.usp.br/tradterm 


\section{Apêndice I}

Original e as duas versões do texto de partida para o inglês.

TEXTO DE PARTIDA

Pepinos e abobrinhas

Galinha velha é que dá caldo bom?

E quem nunca chorou pelo leite derramado

ou puxou a brasa pra sua sardinha?

- Você pensou em como resolver aquele pepino que eu te passei?

- Na verdade ainda tem muita coisa pra digerir naquele relatório, mas de cara já dá pra dizer que o camarada era um tremendo laranja.

- Pois é. Será que em nenhum momento ele percebeu que aquele angu ia desandar?

- Estranho, né? Ele ficou anos ali, fazendo só o feijão-com-arroz e ganhando uma tremenda grana.

- E ele sempre soube que o Pedro e o Madeira eram farinha do mesmo saco.

\section{VERSÃO 1}

Hot potatoes and baloney

Is there many a good tune played on an old fiddle?

Who never cries over spilled milk or tooks out for number one?

- Have you thought about how to handle that hot potato I tossed you?

- Actually, in that report, there are still a lot to process, but you can tell it straight away that that buddy was a straw-man.

- Isee. Iwonder if he didn't realize by any means that there was something fishy about it.

- That's weird, isn't it? He was there for years, worrying only about bread-and-butter and earning much money.

- And he always knew that Pedro and Madeira were tared with the same brush.
VERSÃO 2

\section{Hot potatoes and Baloney}

There's many a good tune played on an old fiddle?

Who has never cried over spilled milk or feathered their own nest?

- Have you thought about how to handle that hot potato I passed on to you?

- Actually, there is still a lot to digest in that report; but one can clearly see that the guy is a complete strawman.

- Yeah. Didn't he realize his goose was cooking?

- Weird, huh? He stayed there for years doing bread-and-butter and making lots of money.

- He has always known that Pedro and Madeira were two peas in a pod.

TradTerm, São Paulo, v.37, n. 2, janeiro/2021, p. 397-429

Número Especial - Linguística de Corpus

www.revistas.usp.br/tradterm 
- Quer saber? Eu avisei. Eu cansei de falar pro camarada que tinha muita coisa esquisita rolando. Cansei de dizer que ele precisava ficar com um olho no peixe e o outro no gato.

- Não adianta, cara. Tem gente que é assim mesmo. Tem gente que não percebe que a rapadura é doce, mas não é mole.

- Aí quando o caldo entorna...

- Aí não adianta chorar pelo leite derramado.

- E, mudando de pato pra ganso como é que ficou o contrato com o Zé Ernesto?

- Eu tô sentindo que eles estão enchendo lingüiça.

- Calma. Você sabe que quem tem pressa come cru.

- Eu sei, mas uma coisa é você perceber que te colocaram em banho-maria e outra é sentir que te colocaram na geladeira.

- Paranóia sua. Eles se meteram naquela empreitada lá no norte...

- Aquilo todo mundo sabia que era um tremendo de um abacaxi.

- E o Andrade é um osso duro de roer.
- You know what? l've warned him. l'm d-one talking to him that there were a lot of weird stuff going on. I'm done telling him that he needed to keep his eyes wide open.

- It-won't help at all, dude. That's the way he is. Such people doesn't realize that things are not so simple.

- When one rocks the boat...

- It doesn't do any good to cry over spilled milk.

- Changing the subject, how did it get the contract with Zé Ernesto?

- I'm sensing that they're just waffling on.

- Calm down. You know that haste makes waste.

- I know it, but one thing is to notice that somebody is stalling and other thing is to feet that we've been getting the cold shoulder.

- You're paranoid. They put themselves in that contract work in the north..

- Everybody knew that that was a complete temon.

- And Andrade's a hard nut to crack.
- You know what? I told him so. I got tired of telling him that there was something fishy going on. And that he should keep his eyes wide open.

- It's useless, man. Some people are just like that. Some people don't realize that good things don't come easy.

- Then, when one rocks the boat...

- Then, there's no use crying over spilled milk.

- Now moving on from chalk to cheese, what happened with the contract with Zé Ernesto?

- I have a feeling they're just waffling.

- Take it easy. You know that haste makes waste.

- I know, but one thing is to be stalled, and another one is to be given the cold shoulder. - You're paranoid. They got involved in that endeavor in the North...

- Everybody knew that was a huge hot potato.

- And Andrade is a hard nut to crack.

TradTerm, São Paulo, v.37, n. 2, janeiro/2021, p. 397-429

Número Especial - Linguística de Corpus www.revistas.usp.br/tradterm 
- Por isso eles não estão querendo sumir agora esse novo contrato.

- Eu cheguei a conversar com o Zé e ele tinha certeza que ia ser mel na sopa.

- Lembro bem. Mas esse é o Zé Ernesto. É só você insinuar que ele pode, eventualmente, vir a ter algum problema que ele já conclui que você tá querendo puxar a brasa pra tua sardinha.

- Sem falar que aquele assunto de Belo Horizonte não tinha sido resolvido.

- Querer assobiar e chupar cana ao mesmo tempo dá nisso.

- O Freitas te passou o relatório de Petrópolis?

- Uma verdadeira salada. O Freitas não anda muito bem. Aliás, nem veio trabalhar.

\section{- Ligou pra ele?}

- Disse que é a tal da virose que tá dando por aí e vai ficar em casa de molho.

- Falando nisso, você acha que aquela proposta do Derek pode dar algum caldo?

- A minha dúvida é a mesma: quero saber com qual fatia do bolo a gente fica.
- That is why they won't be taking over-this new contract now.

- I got to talk to Zé and he was sure that it was going to be a piece of cake.

- I remember it well. But it is Zé Ernesto. If you only imply that he may, eventually, come to have any trouble he already concludes that you are tooking out for number one.

- Not to mention that that Belo Horizonte matter hadn't been solved.

- It ends like this, for you can't have your cake and eat it.

- Did Freitas passed on to you the Petrópolis report?

- It's a complete mess. Freitas isn't feeling so well. Actually, he didn't even came to work.

\section{- Have you called him?}

- He said that he is sick and is going to stay at home.

- By the way, do you think that Derek's proposal will work out?

- I've got the same doubt: I want to know what's ouf piece of the pie.
- That's why they don't want to take this contract over.

- I even talked to Zé and he was sure it was going to be a piece of cake.

- I remember it well. But this is how Zé Ernesto is. If you merely imply he may occasionally have any trouble, he concludes you are feathering your own nest.

- Not to mention that Belo Horizonte lemon, that wasn't finished by then.

- That's what happens when one tries to have one's cake and eat it too.

- Has Freitas passed you the Petrópolis report?

- A real mess. Freitas hasn't been feeling so well lately. Actually, he didn't even come to work.

- Did you call him?

- He said it's because of the bug that is going around, and that he'll bed rest.

- By the way, do you think Derek's proposal will bear any fruit?

- I've got the same doubt: which piece of the pie do we stay with?

TradTerm, São Paulo, v.37, n. 2, janeiro/2021, p. 397-429

Número Especial - Linguística de Corpus www.revistas.usp.br/tradterm 
- O cara é guloso.

- E gosta de moleza, gosta de sentar no pudim e costuma não colocar a mão na massa.

- Chegou a ver o orçamento dele?

- Só gordura.

- A cara dele. Reparou como ele engordou?

- Tá pior que gato de cozinheira.

- E na reunião com os investidores suava mais que pano de cuscuz.

- Gostei da secretária dele.

- Que biscoitão, hein?

- Eu cheguei a bater um papinho com ela. $\mathrm{Na}$ verdade é meio sem sal.

- He-is a greedy guy.

- He likes the easy things, he likes things to be at the push of a button, and he doesn't like to get his hands dirty.

- Have you got to see his budget?

- It's only fat.

- It's so him. Have you noticed how he's put on some weight?

- He is always stuffing his face.

- And in the meeting with the investors he was sweating like a pig.

- I liked his secretary.

- What a knockout, huh?

- I got to have a small chat with her. Actually, she's dull.

- Mas é bem melhor que a dona Neide.

- A dona Neide. Sabia que ela teve seus dias de glória?

- Mas virou um bagaço.

- Se você conversar com o Elias ele vai discordar.

- E engraçado o Elias. Ele bate firme na mesma tecla há anos: galinha velha é que dá caldo bom.
- But she is much better than Mrs. Neide.

- Mrs. Neide. Did you know that she had already her glory days.

- But now she is worned-out.

- If you talk to Elias he'll disagree.

- Elias, he-is funny. He harps about it for years: There's many a good tune played on an old fiddle.
- He's a greedy guy.

- He likes cakewalk, duck soup, and is not used to getting his hands dirty.

- Did you get to see his budget?

- Just fat.

- It's so him. Have you noticed how he's put some weight on?

- He's worse than a fat pig.

- In the meeting with the investors, he was sweating like one.

- I liked his secretary.

- What an eye candy, huh?

- I did have a little chat with her. Actually, she is plain vanilla.

- But she is way better than Ms. Neide.

- Ms. Neide. You know, she has had her glory days...

- But now, she's like leftovers.

- If you talk to Elias he'll disagree.

- Elias, he's funny. He harps the same string for years: there's many a good tune played on an old fiddle.

TradTerm, São Paulo, v.37, n. 2, janeiro/2021, p. 397-429

Número Especial - Linguística de Corpus www.revistas.usp.br/tradterm 

- A gente acabou entrando na parada lá de
Goiás?

- Entramos, mas bem de leve. Ali o que eu acho é que a gente deve ir comendo pelas beiradas.

\section{- É no fogo baixo que o feijão engrossa.}

- Marília. Vale a pena requentar essa história?

- Tenho dúvidas. Acho que é bananeira que já deu cacho.

- Não concordo totalmente, mas admito que é tirar leite de pedra.

- Have we ended up into that Goiás matter?

- Yes, but, slightly. What I think is that we should go slowly.

- Things take time to happen.

- Marília. Do you think it-is worth it to talk about this story again?

- I've got doubts. think there's no use.

- I don't completely agree, but I admit that it is getting blood out of a stone.

- Are you going to Alonso's this Saturday?

- I'll try to. By the way, have you seen his house?

- Some people said that it is a mansion.

- Disseram que é uma mansão.

- It is. But the guy have built a 3937 feet

- É. Mas o cara fez uma casa de 1.200 metros em um terreno de 1.300 metros.

- 0 clássico peru no pires.

- Tá com muito, o Alonso.

- E quem tem muito, dizia minha avó, assa manteiga no espeto.

- Ficou sabendo do Caio?

- Caio Mendes? house in a 4265 feet land.

- Alonso, he's got too much

- My grandma used to say that-whoever has too much do unpredictable things.

- Did you get to know about Caio?

- Caio Mendes?
- Have we ended up involved in that Goiás stuff?

- Yes, but slightly. In that case, I think we should know which side of our bread is buttered.

- Great oaks from little acorns grow.

- Marília. Do you think it's worth bringing this story back?

- I'm not sure. It's not worth a hill of beans.

- I don't completely agree, but I admit that it is getting blood out of a stone.

- Are you going to Alonso's this Saturday?

- I'll try to. By the way, have you seen his house?

- I heard it's a mansion.

- It is. But the guy has built a 13,000 sq. ft. house in a 14,000 sq. $\mathrm{ft}$. piece of land.

- Packed in like sardines.

- Alonso, he's loaded.

- And as my grandma used to say, those who have too much pour money down the drain.

- Have you heard about Caio?

- Caio Mendes?

TradTerm, São Paulo, v.37, n. 2, janeiro/2021, p. 397-429

Número Especial - Linguística de Corpus www.revistas.usp.br/tradterm 
- Fritaram ele.

- Tá brincando!

- Não faz 15 dias, a gente foi tomar uma coisinha lá no Patá e ele tava se queixando que o pessoal só via as pingas que ele bebia, mas não via os tombos que ele levava.

- Talvez tenha sido melhor, sabia? Aquela empresa não vai bem, cara. $\mathrm{E}$ aí a gente sabe: em casa onde não tem pão, todo mundo grita...

\section{- E ninguém tem razão.}

- Vai almoçar?

- É bom. Não sei por que, mas essa nossa conversa me abriu o apetite.
- He got fired.

- Are you kidding me?

- It hasn't even been 15 days, we went to Patá for a drink and he was complaining about how people see only one side of the story.

- Maybe it was better off like this, you know? That company is not doing well, man. And we know that in lack of food, nobody knows what they do...

\section{- And no one is right.}

- Will you have lunch?

- It's good to. I don't know why, but our talk made me hungry.
- He got fired.

- Are you kidding?!

- Less than 15 days ago we went to Patá for a drink and he was complaining about how people don't see that one can't make an omelet without breaking eggs.

- Maybe it was better off like this, you know? That company is not going well, man. And we know that when poverty comes in at one's door...

- Love flies out of the window.

- Are you going to have lunch?

- Good idea. I don't know why, but our talk made me hungry.

TradTerm, São Paulo, v.37, n. 2, janeiro/2021, p. 397-429

Número Especial - Linguística de Corpus

www.revistas.usp.br/tradterm 